\title{
RESULTS OF EARLY SURGERY FOR INFANTILE ESOTROPIA IN NORMAL AND NEUROLOGICALLY IMPAIRED INFANTS
}

\author{
S. J. CHARLES and A. T. MOORE \\ Cambridge
}

\begin{abstract}
SUMMARY
A prospective study was performed over a 4-year period of 56 infants presenting with infantile esotropia to assess development of binocularity after surgical alignment before 2 years of age. In $50 \%$ of cases infantile esotropia was associated with neurological problems or prematurity. Forty-three cases have undergone surgery (mean age 15.7 months \pm 3.46$)$; $86 \%$ were aligned ( \pm 10 dioptres) at 2 years. Eighty-seven per cent of normal children and $74 \%$ of children with neurological problems or prematurity were aligned at last follow-up (mean 27.2 months since surgery). Tests of fusion and stereopsis have to date been possible upon 21 'successfully' aligned infants and although most have evidence of peripheral sensory fusion none showed stereopsis to more than one test. Although early surgery achieves a good cosmetic result in normal children and those with neurological problems, our findings question its ability to promote the development of even gross stereopsis in most children.
\end{abstract}

Infantile esotropia is a form of esodeviation with an onset before 6 months of age. It is characterised by a stable large-angle esotropia, without significant refractive error, often with amblyopia and nystagmus and later onset of dissociated vertical deviation (DVD) and inferior oblique overaction. ${ }^{1.2}$ Potential for normal binocular single vision is limited but early surgical alignment is reported to promote binocularity. ${ }^{2-6}$ Ing $^{7}$ retrospectively studied a large series of infantile esotropes aligned within \pm 10 prism dioptres of orthotropia and found those aligned before the age of 2 years to have significantly more binocular function than those aligned later. Since alignment appears to be the prerequisite for development of binocularity surgery as early as 4 months of age has been suggested, ${ }^{8}$ although Ing ${ }^{7,9}$ reported no significant difference in functional result between those aligned at 6 months and those aligned at 12 and 24 months of age.

Correspondence to: Mr. Stephen Charles, FCOphth, Department of Ophthalmology, Addenbrooke's Hospital, Cambridge CB2 2QQ, UK.
In 'essential' infantile esotropia there is no associated neurological abnormality but early-onset esotropia is common in premature and neurologically impaired children. ${ }^{1,10}$ Surgery in this group is often delayed ${ }^{10,11}$ and the results of surgery are less satisfactory.

Since 1987 we have performed a prospective study of all infants, both normal and premature or neurologically impaired children, presenting to Addenbrooke's Hospital with infantile esotropia. Both groups have been treated in the same way, to assess the results of surgical alignment before the age of 2 years on alignment and binocular function. This paper reports the results of this study.

\section{PATIENTS AND METHODS}

Infantile esotropia was defined as esotropia with onset before 6 months of age confirmed by ophthalmic examination or on the basis of photographs taken before the age of 6 months with ophthalmic examination before the age of 12 months. ${ }^{2}$ Patients with Duane's syndrome, sixth nerve palsies, accommodative esotropia or ocular abnormalities such as optic atrophy or optic nerve hypoplasia were excluded. All children were refracted and any abnormal refractive errors fully corrected pre-operatively. Occlusion treatment was used if a fixation preference was present.

Surgery was performed by a single surgeon (A.T.M.) when examination revealed a stable and large-angle esotropia with alternating fixation. Bimedial rectus recessions to $10.5 \mathrm{~mm}$ from the limbus were performed, via a limbal incision. These were combined with unilateral lateral rectus recession for squints greater than 55-60 dioptres (three-muscle surgery) except in the neurologically impaired group. If inferior oblique overaction was evident at the time of primary surgery, inferior oblique recessions were performed at the same time. Postoperatively stereopsis was assessed using the Titmus, Frisby and TNO stereotests. A subject was said to have positive stereopsis when there were positive responses to

Eye (1992) 6, 603-606 
Table I. Associated features of amblyopia (as assessed by fixation preference at presentation), dissociated vertical deviation (DVD) and inferior oblique overaction in normal children with infantile esotropia and in those with neurological problems and/or prematurity

\begin{tabular}{lll}
\hline Associated feature & $\begin{array}{c}\text { Normal } \\
(\%)\end{array}$ & $\begin{array}{c}\mathrm{CP} / \text { prematurity } \\
(\%)\end{array}$ \\
\hline Amblyopia & 50 & 63 \\
DVD & & \\
$\quad$ Overall & 42.9 & 20 \\
$\quad$ >30 months age & 50 & 29.4 \\
Inferior oblique overaction & & 28 \\
$\quad$ Overall & 53.6 & 41.2 \\
$\quad>30$ months age & 77.8 & \\
\hline
\end{tabular}

at least two of the tests (e.g. seeing the Titmus fly alone was a negative result). Sensory fusion was tested using Worth 4 dot lights and Bagolini striated glasses at $0.3 \mathrm{~m}$ and $6 \mathrm{~m}$.

\section{RESULTS}

\section{Aetiology}

Fifty-six infants presented with infantile esotropia from 1987 to 1991 . Twenty-eight were normal infants, but 28 were either premature ( $\leqslant 36$ weeks gestation) and/or had associated neurological problems. In this group, 21 infants were premature but in 15 there was associated neurological abnormality (cerebral plasy (CP), hydrocephalus, meningomyelocoele).

\section{Features}

Associated ophthalmological features for the two groups are summarised in Table I. Evidence of amblyopia as measured by a fixation preference was present in at least $50 \%$ of both the normal and the $\mathrm{CP} /$ premature groups. DVD was present in $50 \%$ and inferior oblique overaction in $77.8 \%$ of those normal children over 30 months of age. DVD and inferior oblique overaction were also present in the $\mathrm{CP} /$ premature group but to a lesser extent.

\section{Surgery}

Forty-three patients have so far undergone surgery: 33 had bimedial rectus recessions (including $19 \mathrm{CP} /$ premature infants), 3 had bimedial rectus recessions combined with bilateral inferior oblique recessions and 7 had threemuscle surgery. Mean pre-operative angle was 51.3 dioptres ( \pm 11.1 , range $25-75$ dioptres) and mean age at surgery was 15.7 months ( \pm 3.46 , range 9-23 months). Secondary surgery has so far been required in 14 cases: 8 for horizontal surgery ( 6 for residual esotropia and 2 for exotropia), 5 for inferior oblique overaction and 1 for DVD.

\section{Alignment}

At 2 years of age 37 patients $(86 \%)$ were within 10 dioptres of orthotropia. Thirty-three retained this alignment (77\%; mean age 42.9 months \pm 17.3 , range $13-71$ months) but 2 patients had a residual esotropia and 2 had consecutive exotropia. At the most recent review 35 of the
43 patients who had received surgery $(81.4 \%)$ were within 10 dioptres of orthotropia (mean age 43.5 months \pm 17.5 , range 13-71 months). Mean follow-up was 36.6 months ( \pm 17.1 ; range 6-68 months). Of the normal children $87.5 \%(20 / 24)$ were within 10 dioptres of orthotropia as were $73.7 \%(14 / 19)$ of the $\mathrm{CP} /$ premature children.

\section{Binocular Function}

Testing of binocular function was possible in 21 of the 37 children who had been successfully aligned at 2 years of age (13 normal, $8 \mathrm{CP} /$ premature; mean age 4.25 years). None gave a positive stereoscopic response to two of the three tests (Frisby, Titmus or TNO) although 4 gave a positive response to one of the tests alone (1 Frisby 600 seconds of arc; 1 Titmus 400 seconds; 2 Titmus fly 3000 seconds). One of these children suffered from cerebral palsy. There was no age difference between those showing a response to one stereopsis test and those who did not: the mean age of those with a positive response to one test was 54.8 months $( \pm 10.1)$ compared with 53.8 months $( \pm 10.1)$ for those with no stereopsis.

Tests of sensory fusion gave reliable results in 12 children (see Table II). Eight demonstrated peripheral fusion on testing with Worth 4 dot lights at $0.3 \mathrm{~m}$.

\section{DISCUSSION}

This study has considered all infants presenting with esotropia of onset before 6 months of age. Early-onset esotropia was associated with neurological impairment and/or prematurity in $50 \%$ of cases, which is in broad agreement with figures of $30-60 \%$ in other studies..$^{10,12}$ Many of these infants developed DVD and inferior oblique overaction similar to 'essential' infantile esotropes, suggesting that there may be a similar aetiology for the strabismus. Neurological problems are common in infants presenting with infantile esotropia. These children may have a worse prognosis for successful alignment after surgery ${ }^{10}$ and delayed surgery to allow complete stability of the deviation has been advocated. ${ }^{11,13}$ Since early surgery gives better results in normal infants, the poor results of surgery in infants with neurological problems might be, in part, related to the more conservative delayed treatment given to these infants. We have performed early surgery to gain alignment by the age of 2 years in both the 'essential' infantile esotropia cases and those associated with neurological problems or prematurity. To date only one child with cerebral palsy has shown binocular function but most have maintained stable alignment. Almost three-quarters (74\%) of the $\mathrm{CP} /$ premature group were within 10 dioptres

Table II. Results of tests using Worth 4 dot and Bagolini glasses in 21 infantile esotropes who had been successfully aligned at 2 years

\begin{tabular}{lcccc}
\hline Test & $\begin{array}{c}\text { Distance } \\
(\mathrm{m})\end{array}$ & $\begin{array}{c}\text { Binocular } \\
\text { response } \\
(n)\end{array}$ & $\begin{array}{c}\text { Suppression } \\
(n)\end{array}$ & $\begin{array}{c}\text { Inconclusive } \\
(n)\end{array}$ \\
\hline Worth 4 dot & 0.3 & 8 & 4 & 9 \\
Bagolini & 6.0 & 5 & 6 & 10 \\
& 0.3 & 8 & 4 & 9 \\
& 6.0 & 5 & 7 & 9 \\
\hline
\end{tabular}


of orthotropia compared with $83 \%$ of normal children, suggesting that there is little point in delaying surgery in the child with neurological problems if there are no contraindications to an anaesthetic.

There is a surprising variation in the sensory results reported in children with essential infantile esotropia who are successfully aligned. Some retrospective studies have suggested that if patients are aligned before the age of 24 months the majority (at least 60\%) will develop both 'gross' stereopsis (200-3000 seconds of arc) and sensory fusion, ${ }^{7,14}$ but more recent studies suggest that stereopsis develops in a minority of successfully aligned patients. ${ }^{2,5,6,15} \mathrm{Ing}^{7}$ achieved stereopsis in a majority of patients but this was a retrospective multicentre study such that ascertainment bias may have been possible. Studies reporting stereopsis in a substantial proportion of patients have tended to use polaroid vectographic stereotests ${ }^{7,14}$ which may offer monocular clues. ${ }^{16}$ In one study stereoacuity up to 40 seconds of arc was reported ${ }^{14}$ but the patient group included cases of inconcomitant squint and Duane's syndrome, which have a greater potential for binocularity. In contrast, von Noorden rarely found stereopsis in a large group of treated infantile esotropes ${ }^{2}$ and Helveston et al. ${ }^{17}$ found no infantile esotropes operated on before 12 months of age to develop stereopsis. Helveston suggested that there might be two types of infantile esotropia: with or without potential for fusion.

There have been few prospective studies: Birch et al. ${ }^{5}$ found $35 \%$ of infantile esotropes with a fixation preference, operated on before 1 year of age, to have gross stereopsis to random-dot stereograms ( 550 seconds or better), but a similar longitudinal study by Dobson and Sebris ${ }^{15}$ showed no stereopsis in any of their corrected infantile esotropes.

Despite successful alignment none of our patients had stereopsis demonstrable on more than one test although 4 (19\%) had stereoposis for one test alone (400-3000 seconds of arc). Positive tests were seen with the Frisby and Titmus tests, both of which may provide monocular clues. ${ }^{18}$ Previously published studies on part of the same patient population, ${ }^{19,20}$ using forced-choice preferential looking (FPL) and a dynamic random-dot stereogram with coarse disparity ( 42 minutes of arc), showed stereopsis in the early post-operative period which was found in only a few patients when retested 2 years after surgery. A period of strabismus in the first year of life appears to disrupt the normal development of binocularity which is not corrected by surgical alignment. This view is supported by experimental evidence in infant monkeys where artificial strabismus of short duration produced an irreversible loss of striate binocular neurons. ${ }^{21,22}$ This suggests that defective stereopsis in infantile esotropes may be a consequence of strabismus in early infancy rather than the manifestation of a primary sensory defect. ${ }^{23}$

In the absence of normal binocular function, what is it that maintains alignment in the post-operative period in infantile esotropia? Peripheral fusion has been reported in about half of treated infantile esotropes in other studies, ${ }^{6.24}$ a finding in broad agreement with this study. Therefore, peripheral fusion may be sufficient to maintain alignment.

This study confirms that the surgical treatment of infantile esotropia before 2 years of age gives stable alignment in a majority of patients with evidence of sensory fusion. The debate is about whether these successfully aligned patients develop stereopsis. There is a wide variation in results which may be related in part to patient selection, length of follow-up, and the type of stereotest used. In contrast to the prospective study of Birch et al. ${ }^{5}$ we have found no convincing evidence of stereopsis in our patients using a positive result in two stereotests as the criterion for stereopsis. A larger multicentre prospective study of binocularity after early treatment of infantile esotropia is required, but if this were to confirm our poor results of stereopsis it leaves open the question as to whether even earlier surgery might give a better result.

S.J.C. is in receipt of a Wellcome Trust Vision Research Fellowship. The authors thank the members of the Orthoptic Department, Addenbrooke's Hospital, for their help in this project.

Key words: Infantile estotropia, Stereopsis.

\section{REFERENCES}

1. Nelson LB, Wagner RS, Simon JW, et al.: Congenital esotropia. Surv Ophthalmol 1987, 31: 363-83.

2. von Noorden GK: A reassessment of infantile esotropia: XLIV Edward Jackson Memorial Lecture. Am J Ophthalmol 1988, 105: 1-10.

3. Taylor DM: How early is early surgery in the management of strabismus? Arch Ophthalmol 1963, 70: 752-6.

4. Ing M, Costenbader FD, Parks MM, et al.: Early surgery for congenital esotropia. Am J Ophthalmol 1966, 61: 1419-27.

5. Birch EE, Stager DR, Berry P et al.: Prospective assessment of acuity and stereopsis in amblyopic infantile esotropes following early surgery. Invest Ophthalmol Vis Sci 1990, 31: 758-65.

6. Pratt-Johnson JA: Fusion and suppression: development and loss. J Pediatr Ophthalmol Strabismus 1992, 29: 4-11.

7. Ing M: Early surgical alignment for congenital esotropia. Ophthalmology 1983, 90: 132-5.

8. Helveston EM, Ellis FD, Plager DA et al.: Early surgery for essential esotropia. J Pediatr Ophthalmol Strabismus 1990, 27: 115-18.

9. Ing MR: Early surgery for essential infantile esotropia. $J$ Pediatr Ophthalmol Strabismus 1991, 28: 119.

10. Holman RE and Merritt JC: Infantile esotropia: results in the neurologically impaired and 'normal' child at $\mathrm{NCMH}$ (six years). J Pediatr Ophthalmol Strabismus 1986, 23: $41-5$.

11. Willshaw HE and Keenan J: Strabismus surgery in children: the prospects for binocular single vision. Eye 1991, 5: 338-43.

12. Robb RM and Rodier DW: The variable clinical characteristics and course of early infantile esotropia. J Pediatr Ophthalmol Strabismus 1987, 24: 276-81.

13. Hiles DA, Wallar PH, McFarlane F: Current concepts in the management of strabismus in children with cerebral palsy. Ann Ophthalmol 1975, 7: 789-98.

14. Taylor DM: Is congenital esotropia functionally curable? Trans Am Ophthalmol Soc 1972, 70: 529-76.

15. Dobson V and Sebris SL: Longtitudinal study of acuity and stereopsis in infants with or at-risk for esotropia. Invest Ophthalmol Vis Sci 1989, 30: 1146-58.

16. Cooper J and Feldman J: Depth perception and stereopsis. Br J Ophthalmol 1981, 65: 510. 
17. Helveston EM, Ellis FD, Schott J et al.: Surgical treatment for congenital esotropia. Am J Ophthalmol 1983, 96: 218-28.

18. Simons K: A comparison of the Frisby, random-dot E TNO, and random circles stereotests in screening and of fice use. Arch Ophthalmol 1981, 99: 446-52.

19. Smith JC, Atkinson J, Anker S, Moore AT: A prospective study of binocularity and amblyopia in strabismus infants before and after corrective surgery: implications for the human critical period. Clin Vis Sci 1991, 6: 335-53.

20. Atkinson J: Early visual development: differential functioning of parvocellular and magnocellular pathways. Eye 1992, 6: $129-35$.
21. Crawford MLJ and von Noorden GK: Optically induced concomitant strabismus in monkeys. Invest Ophthalmol Vis Sci 1980, 19: 1105-9.

22. Crawford MLJ, Smith EL, Harweth RS et al.: Stereoblind monkeys have few binocular neurons. Invest Ophthalmol Vis Sci 1984, 25: 779-81.

23. von Noorden GK: Current concepts of infantile esotropia. Eye 1988, 2: 343-57.

24. Walker JW, Taylor D: Post-operative early onset esotropia: what is it that keeps them straight? In: Ravault AP and Lenk M, eds. Transactions of the Fifth International Orthoptic Conference, Cannes. LIPS Publishers, 1983: 183-91. 